\title{
APPLICATION OF HYDRODYNAMIC CAVITATION TREATMENT \\ OF HIGH-VISCOSITY OILS FOR THE PURPOSE OF INCREASE OF EFFICIENCY \\ OF TRANSPORTATION
}

• • ершинин, . • р нд, • • остов я

S. V. Vershinina, A. E. Brand, N. A. Mostovaya

юменский госуд рственный нефтег зовый университет, г. юмень,

нститут технологии и бизнес, г. ходк

лючевые слов : гидродин мическ я к вит ция; коррозия; высоковязк я нефть; пункт подогрев Key words: hydrodynamic cavitation; corrosion; heavy oil; crude oil heating

течение последних двух десятилетий н блюд ется тенденция ухудшения к чественного состояния сырьевой $б$ зы нефтяной промышленности, что связ но в основном со зн чительной выр боткой высокопродуктивных месторождений. 
все большую роль в нефтяной отр сли игр ют з п сы высоковязких нефтей, $\mathrm{p}$ зр ботк которых является весьм перспективной вследствие особых реологических свойств.

о д нным четной п л ты , ресурсн я $6 з$ л нсовых 3 п сов нефти оссии оценив ется в 25,2 млрд т, из них з п сы высоковязких нефтей сост вляют 7,2 млрд т, то есть 28,6 \% от общероссийских. ри этом 3,17 млрд т высоковязких нефтей прин длежит территории юменской обл сти, основн я ч сть их р спол г ется в м ло- енецком втономном округе [1].

ысокий ресурсный потенци л месторождений высоковязких нефтей обусловлив ет необходимость постоянного совершенствов ния технологий тр нспортировки, основным огр ничением которого являются реологические свойств и, к к следствие, м лые скорости тр нспортировки и большие экономические 3 тр ты. рименяемые в н стоящее время методы и средств по увеличению эффективности процесс тр нспортировки являются прежде всего з висимыми от экономических условий в стр не в условиях экономической нест бильности.

роведенный н лиз пок з л, что экономическ я эффективность системы тр нспортировки высоковязких нефтей в оссии х р ктеризуется м лой рент бельностью, и в связи с этим нефтяные комп нии ежегодно выделяют большие фин нсовые ресурсы н совершенствов ние процесс тр нспортировки и изменение реологических свойств высоковязких нефтей. н стоящее время н иболее р спростр ненными способ ми обр ботки сырья с целью достижения больших скоростей тр нспортировки являются: термический н грев; доб вление прис док и р зб вителей; применение электром гнитного излучения.

ермический н грев - с мый р спростр ненный и эффективный, но одновременно и с мый дорогостоящий метод обр ботки, осуществляемый с помощью подогрев телей нефти. о д нным « р нснефть - ибирь», н всей протяженности м гистр льного нефтепровод « полярье - урпе» с пл нируемой пропускной способность 30 млн т будет построено восемь пунктов подогрев нефти с целью обр ботки северной высоковязкой нефти в условиях низких темпер тур [2]. ля предв рительного подогрев нефти в н стоящее время используются печи трубч тые блочного тип ( -10), основные х р ктеристики которых предст влены в т бл. 1.

спортныед нные печи трубч той блочного тип ( -10)

\begin{tabular}{|l|l|}
\hline p метр & еличин \\
\hline роизводительность по продукту & $900 \mathrm{~m}^{3} /$ с \\
\hline опливн я мощность & 4,2 ж/ч с \\
\hline бочее д вление & о 6,4 \\
\hline емпер тур нефти н выходе из печи & не выше 70 \\
\hline отребляемое топливо & риродный г з \\
\hline оличество горелок & 4 шт. -400 \\
\hline ,\% & 71 \\
\hline епловые потери при эксплу т ции, \% & 8 \\
\hline
\end{tabular}

опливом для $\mathrm{p}$ боты т кой печи является природный г 3, с учетом стоимости г 3 для крупных промышленных предприятий м ло- енецкого втономного округ и юменской обл сти (в среднем 2848 руб./м ${ }^{3}$ ) ориентировочные потери н подогрев нефти н величину в $1^{0}$ сост вляют 280000 рублей в год при объеме перек чки в 1 млн т [3-4]. течение год 3 тр ты с пл нируемой пропускной способностью н подогрев сост вят 252 млн рублей без учет поддерж ния темпер туры по длине нефтепровод . сходя из ск з нного, применение более энергоемких и энергоресурсосберег ющих технологий тр нспортировки является кр йне необходимым и кту льным.

о мнению отечественных специ листов, т ких к к ромтов . ., ршов . ., едоткин . ., т кже з рубежных специ листов эммит, , ейли ж. из мерик нского сообществ инженеров-мех ников и комп ний Schlumberger и Halliburton н иболее перспективным методом является гидродин мическ я к вит ционн я обр ботк . положительным х р ктеристик м процесс можно отнести: эффективность, экономичность и возможность использов ть внутренние резервы веществ с целью изменения реологических свойств нефти (структурн я вязкость, темпер тур з стыв ния, н пряжения сдвиг и др.). вление к вит ции возник ет в момент понижения д вления жидкости к д влению н сыщенных п ров жидкости. ри близких зн чениях в жидкости н блюд ется обильное выделение пузырьков (к верн), з полненных р ство- 
ренным г зом [5]. хлопыв ние к верны х р ктеризуется резкими ск чк ми темпер туры и д вления, в результ те которых происходит р спростр нение энергетической волны, котор я р зруш ет близлеж щие углеродистые цепочки и молекулярные соединения, и лок льный н грев. оличество пузырьков может в рьиров ться от $10^{4}$ до $10^{6}$ в одном м ${ }^{3}$. условиях гидродин мической к вит ции явление н блюд ется в мест х сужения и р сширения к н лов.

целью повышения эффективности обр ботки нефти и уменьшения экономической н грузки нефтяных комп ний втор ми р зр бот н метод по уменьшению вязкости нефти и повышению н ч льной темпер туры тр нспортируемой нефти. етод 3 ключ ется в применении к вит ционной обр ботки нефти з счет изменения сечения технологического трубопровод ной и применении щелевых цилиндров (рис. 1).

uc. 1 .

вит ционное оборудов ние

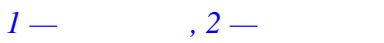

$\kappa$ мер , 3-диффузор с щелевым цилиндром

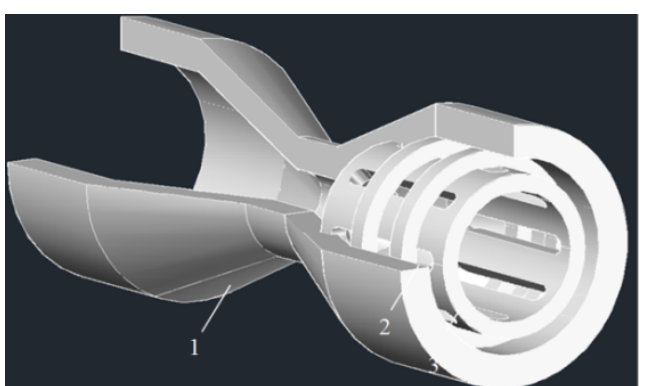

рис. 2 смоделиров н процесс гидродин мической к вит ции в трубе ентури з счет изменения сечения трубопровод с помощью прогр ммного комплекс ANSYS/FLUENT. олученные д нные и з висимости были учтены при проведении л бор торных испыт ний.

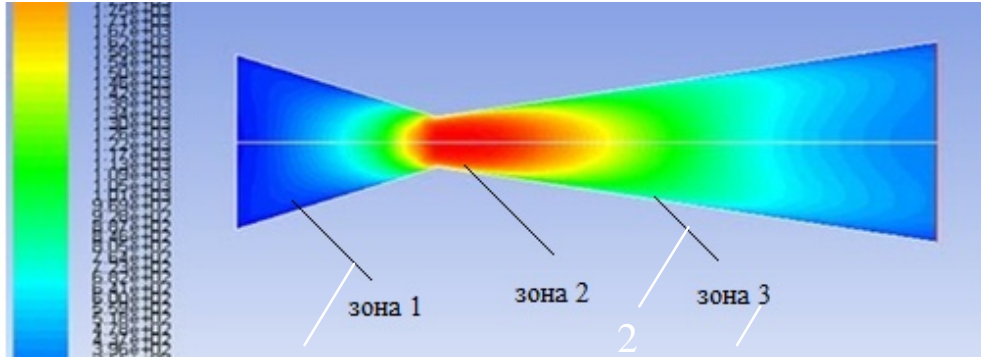

ис. 2. спределение темпер турного поля при к вит ции:

зон 1 - зон предв рительногон грев ; зон $2-$ - он холодного кипения,

зон $3-$ зон ст билиз ции поток и темпер турного поля

оделиров ние пок з ло, что в процессе прохождения высоковязкой нефти через суж ющийся уч сток (зон 2 2) происходит лок льное повышение темпер туры, что является предпосылкой для получения экономической выгоды.

роцесс к вит ции н логичен кипению жидкости, поэтому в к честве критического д вления, при котором возник ет к вит ция, обычно приним ют д вление н сыщенных п ров перек чив емой жидкости при д нной темпер туре, которое определяется согл сно 1756-2000.

иним льн я скорость течения нефти в модуле, необходим я для возникновения к вит ции, определяется по формуле

$$
v_{\kappa в}=\frac{64 \cdot P_{H}}{g \cdot P_{k p}}\left(\frac{29 \cdot \rho \cdot g}{P_{H}}\right)^{1.9},
$$

где кр - критическое д вление к вит ции ( ); н - д вление н сыщенных п ров ( ). еобходимый н пор н сос для возникновения к вит ции 


$$
\kappa=\frac{v_{\kappa}^{2}}{2 g}+h_{M}
$$

где $h_{м}$ - сумм рные потери н пор в модуле, м.

умм рные потери н пор в модуле скл дыв ются из потерь н пор в конфузоре, диффузоре и цилиндрической ч сти модуля и р ссчитыв ются по формуле

$$
h_{M}=\left(\frac{\lambda}{8 \sin \alpha / 2}\left(1-\frac{1}{n^{2}}\right)+\lambda \frac{L_{u}}{d}+\frac{\lambda}{8 \sin \beta / 2}\left(1-\frac{1}{n^{2}}\right)+\sin \beta\left(1-\frac{1}{n_{1}}\right)^{2}\right) \cdot \frac{v_{\mathrm{K}}^{2}}{2 g},
$$

где $\beta$ - угол р скрытия диффузор , гр д.; $\mathrm{n}_{1}-$ степень $\mathrm{p}$ сширения диффузор $\alpha$ - угол р скрытия конфузор , гр д; $\mathrm{n}-$ степень сужения.

ходе л бор торных испыт ний было выявлено, что н именьшие гидр влические потери н блюд ются в конфузор х с углом р скрытия до $40^{\circ}$ и степенью сужения $1,2-3,0$ и в диффузор х с углом р скрытия менее $50^{\circ}$.

онечный вид формулы н пор выглядит следующим обр зом:

$$
\kappa=\frac{v_{\kappa}^{2}}{2 g} \cdot\left(\zeta_{\kappa}+\zeta_{1}+\zeta_{i}+1\right) .
$$

ля определения зн чений реологических свойств и выявления з кономерностей обр ботки втор ми р боты был собр н л бор торн я уст новк по изучению к вит ционного эффект (рис. 3). спытыв л сь депрессорн я прис дк -1 российского производств, было обр бот но около 200 литров высоковязкой нефти $\rho=945 \mathrm{\kappa г} / \mathrm{M}^{3}$ и $v=360 \mathrm{м}$ с.

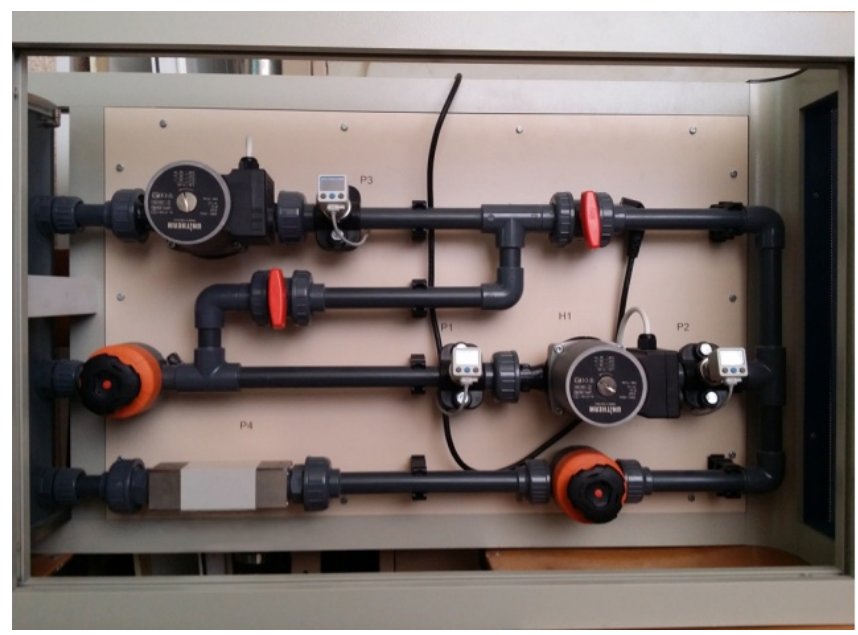

ис. 3. бор торн $я$ уст новк

роведенные исследов ния пок з ли, что к вит ционн я обр ботк нефти является перспективным н пр влением (т бл. 2 и рис. 4$)$.

езульт тык вит ционной обр ботки

\begin{tabular}{|l|c|}
\hline \multicolumn{1}{|c|}{ р ктеристики } & вит ционн я обр ботк \\
\hline епрессия зст, & $5-7$ \\
\hline нижение вязкости, \% & $32-40$ \\
\hline нижение предельно дин мического н пряжения & 4 \\
\hline нижение предельно ст тического н пряжения & $3-4$ \\
\hline ремя восст новления реологических свойств, дней & 4 \\
\hline
\end{tabular}

счет лок льного изменения д вления и, вследствие этого, созд ния условий для к вит ции и р зрыв жидкостной сплошности выделяется энергия, эквив лентн я изменению темпер туры нефти при средней плотности $940 \mathrm{Kr} / \mathrm{m}^{3}$ и вязкости $120 \mathrm{~m} \cdot{ }^{\circ} \mathrm{H}$ $2-3^{0}$. омпьютерн я и ре льн я модель пок з ли сходимость н 94,6\%. связи с возможностью изменения н ч льной темпер туры подогрев нефти меняются и экономические $з$ тр ты [6]. 


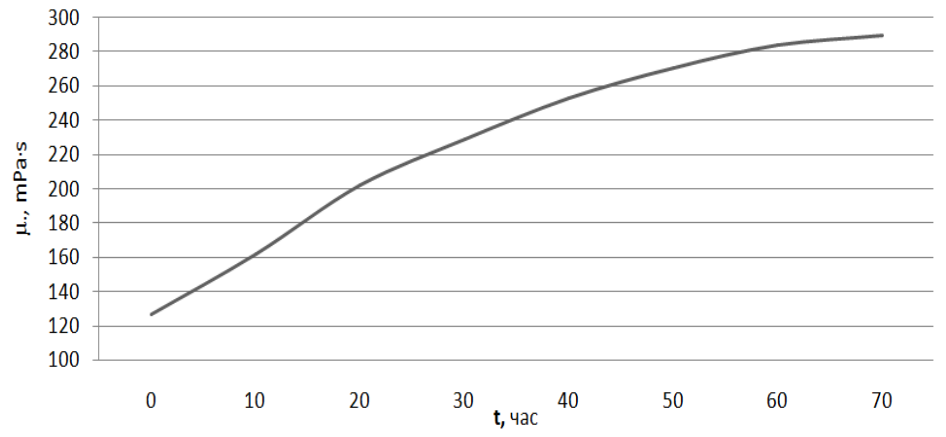

ис. 4. висимостьвосст новления дин мической вязкости от времени рел кс ции

ыводы исследов ния и перспективы д льнейших изыск ний д нного н пр вления.

роведенный втор ми н лиз и р счеты пок зыв ют, что метод к вит ционной обр ботки является эффективным льтерн тивным методом обр ботки высоковязкой нефти. кономическ я целесообр зность и эффективность применения комплексной обр ботки нефти з ключ ется в следующем:

- при к вит ционной обр ботке повыш ется н ч льн я темпер тур подогрев высоковязкой нефти н $2-3^{0}$;

- при комплексном методе уменьш ется вязкость нефти, что в свою очередь приведет к уменьшению з тр ченной мощности подогрев телей и р сход топлив ;

- улучш ются реологические свойств нефти з счет р зрыв углеродистых связей, что позитивно ск жется н д льнейшей тр нспортировке и перер ботке нефти, позволив увеличить выход легколетучих фр кций при тмосферной перегонке.

писок литер турь

1. юменской обл сти // тери лы VI н учно-технической конференции молодежи « «р нснефть» «роблемы трубопроводного тр нспорт нефти».- юмень: еликс, 2005. - . 8-11.

2. «р нснефть - ибирь». - ., 1994-2015. [ лектронный ресурс]. - ежим доступ : http://sibnefteprovod.transneft.ru/press/news/?id=13931. ( т обр щения: 12.03.2015).

3 . « б утверждении оптовых цен н г з, используемых в к честве предельных миним льных и предельных м ксим льных уровней оптовых цен н г з, добыв емый « зпром» и его ффилиров нными лиц ми». рик 3 едер льной службы по т риф м от 26 сентября 2013 г. N 177-э/2 // [ лектронный ресурс]. онсульт нт люс: ерсия роф.

4. «Neftegaz.RU». - ., 2000-2015. [ лектронный pecypc]. - ежим доступ : http://neftegaz.ru/news/view/131972 ( т обр щения: 12.03.2015).

5. Vengerov A. A. Oil cavitation treatment to prevent formation of paraffin deposits / A. A. Vengerov, A. E. Brand // риродные и интеллекту льные ресурсы ибири. ибресурс 2014: м тери лы XV межд. н уч.-пр кт. конф. - емерово: им. . . орб чев , 2014. - .36-37.

6. $\mathrm{p}$ сенко . . . меньшение вязкости нефти методом гидродин мической к вит ции / . . $\mathrm{p}$ сенко,

p нд // риродные и интеллекту льные ресурсы ибири. ибресурс 2014: м тери лы XV межд. н уч.-пр кт. конф. - емерово: им. . . орб чев, 2014. - .44-45.

7. оном рев . роявление сверх ном лии и вязкости н кривых течения высокоз стыв юших нефтей и их смесей / . . оном рев , . . р нд // риродные и интеллекту льные ресурсы ибири. ибресурс 2014: м тери лы XV межд. н уч.-пр кт. конф. - емерово:

8. Stashkovskaya, N. V. Pipelines of innovation and prosperity / N. V. Stashkovskaya, А. Е. Вrand // роблемь функциониров ния систем тр нспорт : м тери лы всерос. н уч.-пр кт. конф. - юмень: юм , 2013. - .25-29

ведения об втор $x$

ериинин ветл н лерьевн, к. э. н., доцент $\kappa$ федры «кономик, орг низ ция и упр вление производством», юоменский госуд рственный нефтег зовый университет, г. юмень, тел 89220426385,e-mail: sversh1978@yandex.ru

р нд льберт ду рдович, студент к федры "р нспорт углеводородных ресурсов», юменский госуд рственный нефтег зовый университет, г. юмень, тел. 89220049327, e-mail: Allbert-@mail.ru

остов я т лья лекс ндровн, студентк к федры " ин нсы и кредит», нститут технологии и бизнес, г. ходк, тел. 89242572709, e-mail: www.rikmail.ru@mail.ru
Information about the authors

Vershinina S. V., Candidate of Science in Economics, associate professor of the chair «Economics, organization and management of production», Tyumen State Oil and Gas University, phone: 89220426385, e-mail: sversh1978@yandex.ru

Brand A. E., student of the chair «Transport of hydrocarbon resources», Tyumen State Oil and Gas University, phone: 89220049327,e-mail: Allbert-@mail.ru

Mostovaya N. A., student of the chair «Finance and credit», Institute of Technologies and Business, Nakhodka, phone: 89242572709,e-mail:www.rikmail.ru@mail.ru 